\title{
AGRESSIVENESS ASSESSMENT IN PRIMARY SCHOOL CHILDREN
}

\author{
Vlad MUNTIANU ${ }^{1 *}$, Beatrice ABĂLAȘEI ${ }^{1}$, Florin TROFIN ${ }^{1}$ \\ “Alexandru Ioan Cuza” University, Faculty of Physical Education and Sports, Iași, Romania \\ *Corresponding author: muntianuvlad96@gmail.com
}

DOI: https://doi.org/10.51267/icpesk2020bp10

\begin{abstract}
We consider it very important to assess children's behaviour and implicitly to understand their way of acting in order to find the most efficient methods and be a continuous support for them. This study aims to observe the behaviour of primary school students with the purpose of assessing their levels of aggressiveness. Being part of the educational system, as physical education teachers, we have always been interested in how children manifest in different situations during school hours. The main method used consisted in determining the 2D:4D ratio, which may have implications for children's behaviour, and gather information about the students' ways of acting, which was obtained by summarising the data from a questionnaire applied to teachers who had daily contact with them. The use of this method made it possible to monitor and measure their aggressiveness levels, the purpose being to intervene in the long term in favour of children with behavioural predispositions by implementing different ways of self-control. We will present some results of the study regarding the average value of aggressiveness, the mean deviation and the $2 D: 4 D$ ratio for both hands: $0.983 \pm 0.0410$ for the left hand and $0.996 \pm 0.047$ for the right hand in boys, and $0.989 \pm 0.003$ for the left hand and $994 \pm 0.039$ for the right hand in girls. In terms of aggressiveness ratio, boys recorded $2.28 \pm 1.33$, and girls, $1.847 \pm 1.103$.
\end{abstract}

Keywords: aggressiveness, children, primary school.

\section{Introduction}

It is well known that, in today's society and especially in our school system, bullying is one of the most important problems that children face. Some of them have a hard time getting past this kind of situations that are absolutely unacceptable in a modern society, because they lead to aggressive behaviour. On the other hand, bullying behaviour may also come from an aggressive background, being a way for students to express their feeling by considering it to be normal. (Ramírez-Granizo et al., 2019)

It is also known that provocation increases aggression but also diminishes the magnitude of gender differences. This suggests that the greater involvement of men in aggression might have its origins in their higher levels of anger from their lower levels of fear and also fear-related inhibition. A review of the relevant literature strongly suggests that there are no gender differences in anger but pronounced differences in fear, especially of physical danger. Three forms of behavioural inhibition (reactive, effortful and self-control) that develop on an infrastructure of fear show negative associations with aggression and gender differences, which generally favours females. Cognitive inhibition shows weaker associations with aggression and inconsistent gender differences. Empathy and guilt, both correlated with inhibition, aggression and gender, are also considered as possible mediators. The relative utility of evolutionary and social role theories in accounting for this pattern of findings is considered.

In the opinion of Björkqvist (2017), it has traditionally been regarded as self-evident that males are more aggressive than females and that this circumstance is directly or indirectly related to testosterone. This concept is supported by the fact that, in most mammals, males are 
more aggressive than females. There are, however, exceptions to this rule: for example, female lemurs and spotted hyenas are more aggressive than their male counterparts.

Some decades ago, the view that females were basically non-aggressive was challenged and explorations into female forms of aggression began. Studies on adolescent aggressive behaviour in Finland (Lagerspetz et al., 1988), based on peer nominations of aggression, identified three different styles of aggressive behaviour: physical aggression, direct verbal aggression and indirect aggression. They found girls to use indirect aggression more than boys. Indirect aggression was conceptualised as social manipulation with the intention to harm the target person psychologically and/or socially, often attacking the target person circuitously, for example through malicious gossip, or otherwise manipulating the social network of the school class in order to lower the victim's standing in the social hierarchy, or perhaps even excluding the victim altogether from a friendship group.

As Hönekopp and Watson (2011) state, males tend to be more aggressive than females, and the organizational effects of prenatal testosterone (T) appear to contribute to this gender difference. Low second-to-fourth digit ratio (2D:4D) is thought to be a marker of high prenatal testosterone. For this reason, a number of studies have used 2D:4D to investigate a potential effect of prenatal $\mathrm{T}$ upon aggression in later life.

Some authors like Donnerstein et al. (1994) believe that the failure of a child to incorporate appropriate standards of behaviour is imperative to be assessed in the way of acting with other persons in order to have a view of their overall behaviour.

In the opinion of Michelson et al. (1983), children in different conflict situations in social life tend to behave aggressively, submissively or assertively, each of them being different. In is also believed that assertive behaviours are more efficient in these conflict situations than submissive and aggressive ones.

There are a lot of factors that can contribute to this type of acting, one of them being related to gender differences. Özgülük and Erdur-Baker (2010) argue that research is needed to explain aggressive behaviour, especially in school-age children. Another factor is represented by the economic and family situation because the living standards are constantly rising, which means that the inability of a family to secure their basic needs may occur, this leading to less time spent with children to educate them properly. Such problematic situations and behaviours endanger children, particularly those who come from disadvantaged family backgrounds.

It is also well known that personality can have implications for children's behaviour (aggressive or not) and, according to their psychological characteristics, they tend to address similar situations differently compared to others.

Donnellan and Robins (2010) summarised some advantages of a personality typology. First, the three personality types (resilient, overcontrolled and undercontrolled) are seen as being able to provide an efficient classification system and proper taxonomy for organizing people at a high level of abstraction. Second, the typological approach shifts attention to the way of organising and integrating traits within individuals. Third, these personality types might serve as efficient moderator variables in order to understand why individuals have various responses when facing the same event. Finally, typological perspectives are useful for bringing personality research to the attention of the general public.

Digit ratios have been shown by Csatho et al. (2003) to correlate with several psychological traits. Women with lower digit ratios report higher, masculinised scores in the Bem Sex Role 
Inventory. Neave et al. (2003) state that men with smaller 2D:4D ratios are perceived as being more masculine and dominant by female observers. Manning et al. (1998) found significant correlations between more masculine (small) digit ratios and achievement, ability and speed in a variety of sports and in visual-spatial ability. More male-like digit ratios are also associated with deleterious traits such as increased rates of autism, immune deficiency and reduced verbal fluency.

Aggression can be seen as "behaviour intended to harm another individual" (Archer, 2009, p. 249) and also shows a sex difference in humans as evidenced by meta-analyses and, more extremely, by homicide statistics, with males showing higher levels of aggression than females. In general, the sex difference in aggression appears to increase with the riskiness of the behaviour and seems to be higher in young children than in adults. As Archer (2009) states, this sex difference may reflect male adaptation to sexual selection pressures. The sex that invests less in offspring (in humans and in most other species, males) has to compete for access to mates, and aggression may be valuable in achieving this. Male adaptations for sexual selection are often under the control of testosterone and subserves male aggression in many species. The effects of circulating $\mathrm{T}$ levels on human aggression appear ambiguous, and $\mathrm{T}$ administration in humans has even been found to increase cooperative behaviour but there is some evidence for organizational effects of prenatal T. Girls and women with congenital adrenal hyperplasia (CAH), a condition that leads to excessive androgen levels during early development, demonstrated significantly higher levels of aggression than controls in two studies with $n=69$ (Mathews et al., 2009) and $n=63$ (Pasterski et al., 2007); a further study by Berenbaum and Resnick (1997) with three smaller samples $(n=15$ to $n=31)$ found mixed results. However, studies on CAH-affected girls are confusing (Cohen-Bendahan et al., 2005; Knickmeyer et al., 2005) and cannot elucidate whether normal within-sex variation in prenatal $\mathrm{T}$ contributes to inter-individual differences in aggression. These data can be used to compare our results, of course, if we are talking about children, but we can say that, according to our results, girls show lower levels of aggression than boys.

As Bailey and Hurd (2004) highlight, more evidence for a relationship between androgen concentration during development and finger ratio comes from children with congenital adrenal hyperplasia $(\mathrm{CAH})$. CAH causes the individual to be exposed to increased levels of androgens from early in gestation to the early neonatal period. Both males and females with $\mathrm{CAH}$, and therefore high developmental androgens, exhibit more masculine finger length ratios than controls but not necessarily when measured on the left hand.

Another problem that comes along with the aggressive behaviour of some children is represented by bullying, a very topical issue nowadays, which represents one of the most common educational problems in schools. Aggressiveness and bullying give rise to tension, conflicts and a negative atmosphere in a social group or classroom. The term "aggressive behaviour" has become relatively often used in our society, be it the aggressive behaviour of individuals or of the whole group.

Bullying may arise from a series of circumstances, some of them being correlated with the physical appearance of some children, which leads to situations in which children judge one another only from this perspective, without having the proper vision and maturity to understand the implications of such behaviour. If we refer to the body mass index (BMI), we can make the assumption that it may have serious implications for children's daily lives, as it has the 
"potential" to affect the physical health status and also psychological aspects, this latter issue being susceptible to lead to an aggressive or borderline way of acting.

In the past decades, we can notice a prevalence of childhood overweight and obesity that has greatly increased all around the world, of course, with some variations across countries from the perspective of levels and trends. Even though the prevalence of childhood overweight and obesity in developing countries remains far below the one in developed countries, a faster growth can be noted in developing countries than in developed ones.

Aggressiveness is a spontaneous characteristic of a person, which serves as a means of survival in unfavourable and life-threatening situations. When uncontrolled, it can show up in the form of instinctive aggressive behaviour. Long-term repetition develops into a form of stabilised behavioural pattern. In this case, it loses its necessary positive function in the social context. In the area of pedagogy, outbursts of anger that are aimed at other people or one's own person or things are classified as "aggressiveness".

The aggressiveness of an individual can be determined biologically by parents through sex hormones (Butovskaya et al., 2013).

As mentioned above, the family background can have implications for children's behaviour. Pereira Falcão and Turini Bolsoni-Silva (2015) state that developmental psychology works to analyse the influence of the behaviours of mothers and fathers on the behaviour of children, and Gomide (2004) also mentions that, when mothers and fathers act as social agents for their children, they are preparing them to behave in society, which leads us the conclusion that the family can really have a great impact on the proper development and evolution of children.

In the family context, it is essential to work with mothers and fathers, mainly because it is believed that childhood behaviour is a result of the child's behavioural history in the environment in which they live and is maintained by environmental-family contingencies.

\section{Methodology}

This study aims to observe the behaviour of primary school students in order to assess their aggressiveness levels. As physical education teachers, this could help us understand children's behaviour so that we can act in predominantly aggressive situations. The main method used consisted in measuring the index and ring fingers to assess the level of aggressiveness, which can also be linked to testosterone and oestrogen levels, with implications for everyday life when correlated with children's family environment, daily behaviour and manifestations throughout the day, information gathered from teachers.

We used the 2D:4D ratio test as the main method of interpreting the results gathered after measuring the target group. Another method used was represented by a questionnaire applied to the teachers who spent most of their time with children on a weekly basis, and we thought they might have a better perspective in assessing their aggression levels.

The 2D:4D ratio involves measuring the index (2) and ring (4) fingers of each hand. Their length was measured from the basal fold to the fingertip using a vernier calliper. The values were expressed in $\mathrm{mm}$ and entered into mathematical processing by relating the index to the ring finger. This test is a good indicator of the level of aggressiveness, being in close connection with testosterone and oestrogen levels. The lower the value of the 2D/4D ratio, the more intense the aggression determined by the internal environment. (Manning et al., 1998) 
For boys, testosterone levels are much better correlated with the 2D:4D ratio for the right hand and with the level of sport performance (Manning \& Hill, 2009).

The aggressiveness of the study subjects was assessed by the teachers they had daily in their classes and with whom they used to spend most of their school time daily. The assessment consisted in applying a questionnaire to teachers, who had to mark the perceived level of children's aggression with numbers from 1 to 5 (1 - non-aggression; 5 - excessive aggression).

Measurements were made on primary school children of different ages, 102 boys and 98 girls from the "Ion Simionescu" School in Iași, in order to assess their levels of aggressiveness and have a better understanding of it and the factors that contribute to children's development.

Each child involved in the study presented a written consent from the parents regarding the assessment and data processing.

Another aspect of the study was to correlate the values of aggression with BMI to get a better picture of aggression and see if these two issues are connected.

Our research starts from the study of the literature and aims to verify two hypotheses. The first assumes that we can measure the levels of aggression in primary school children using the 2D:4D test and that, by correlating it with the questionnaire applied to their teachers, we will be able to notice similarities between them. The second hypothesis assumes that the levels of aggression can show a valid correlation with the body mass index of the tested children, considering this as a factor that stimulates such behaviour.

A first objective of this research is to assess the levels of aggression in primary school children in order to understand them and help them in their continuous development, especially in handling very tense situations.

Another objective is to identify children, if any, who are prone to more aggressive behaviour due to a number of factors (especially the family environment) that might have implications for their daily behaviour.

A third objective is to identify whether there is any connection between aggressiveness levels and body mass index in primary school children, after collecting and interpreting the data obtained through the measurement process.

A primary task, as in any research, is to examine the literature in order to notice the relevance of this topic among researchers around the world. Theoretical substantiation is an important aspect of any research topic because it guides us in achieving our previously set objectives.

Another task is to identify the group on which to make measurements and interpretations about aggressiveness levels. After identifying the group, the next task is to choose the measuring instruments to be used in the practical part of the research.

An important task, after collecting the data obtained from measurements, is to interpret them properly to obtain a relevant picture of the group and its targeted aspects.

The final task is to draw the final conclusions, which gives us the opportunity to make correct statements for the assumptions made in a primary stage of the research.

\section{Results}

We considered it important to assess children's aggressiveness levels because, as physical education teachers, such behaviours may have implications both during classes and for the people around them. 
We summarised and analysed the results of this study using the Graph Pad Prism 6 software, which provided us with the central tendency parameters and the Pearson correlation coefficient of the analysed data series. We aimed to verify if there was a high statistical correlation between the value of the 2D:4D test and the levels of aggressiveness, respectively BMI. The assessment was made using the scale described by Hinkle et al. (2002).

Table 1 shows the demographic and aggression-related data for the group of boys as well as the mean, standard deviation and coefficient of variation for the collected results.

We can notice that, in boys $(8.10 \pm 1.29$ years; $133.40 \pm 9.14 \mathrm{~cm} ; 29.61 \pm 8.52 \mathrm{~kg} ; 16.35 \pm$ $2.88 \mathrm{~kg} / \mathrm{m} 2$ ), the $2 \mathrm{D}: 4 \mathrm{D}$ ratio has a value of $0.98 \pm 0.04$ for the left hand, while for the other hand, the value is higher, $1 \pm 0.05$. The aggressiveness assessed by teachers is below average (3), the value being $2.28 \pm 1.34$. The coefficient of variation for the $2 \mathrm{D}: 4 \mathrm{D}$ test is quite similar for both hands, and the data series can be entered into an intermediate variation ( 4.17 for the left hand and 4.76 for the right hand). Instead, the results of the questionnaire applied to teachers have a very varied distribution.

A study by Butovskaya et al. (2013) on 709 boys and 743 girls with ages between 8 and 17 years $(13.62 \pm 1.98$ years $)$ highlighted that, in boys, the $2 \mathrm{D}: 4 \mathrm{D}$ ratio had the value $0.97 \pm 0.03$ for the right hand and $0.97 \pm 0.03$ for the left hand, the author also presenting the values for the group of girls. The results of this study are lower than the results obtained by us, which involves a higher aggressiveness of those subjects. This is probably due to the age differences between the groups of subjects as well as their psycho-social particularities.

In our study, 98 female subjects are assessed. For the obtained data, we calculated the mean, standard deviation and coefficient of variation. Table 2 shows the demographic and aggressionrelated data for the group of girls. We can see that, in girls (8.12 \pm 1.27 years; $129.80 \pm 8.86$ $\mathrm{cm} ; 28.04 \pm 7.5 \mathrm{~kg} ; 16.39 \pm 2.70 \mathrm{~kg} / \mathrm{m} 2$ ), the $2 \mathrm{D}: 4 \mathrm{D}$ ratio has a value of $0.99 \pm 0.04$ for the left hand and the same value for the right hand. The aggressiveness assessed by teachers is below average (2), the value being $1.86 \pm 1.10$. The coefficient of variation for the $2 \mathrm{D}: 4 \mathrm{D}$ test has mostly the same value, and the data series can be entered into an intermediate variation $(3.79 \%$ for the left hand and $3.98 \%$ for the right hand). The results of the group of girls can also be compared with the study of Bukoskaya (2013), the differences being made mostly by the variation of age and the individual particularities.

Table 3 shows the Pearson correlations of aggression and BMI for the group of boys. The 2D:4D ratio for the right and left hand has the highest positive correlation of aggression, 0.196, and the aggressiveness assessment in the questionnaire is 0.035 .

The highest positive correlation is established by the $2 \mathrm{D}: 4 \mathrm{D}$ ratios of the two hands, the value of Pearson correlation coefficient ( $r$ ) being 0.196, which makes the connection negligible. We can notice a very weak correlation for the 2D:4D ratios of the two hands and the aggressiveness assessed by teachers. As regards the connection between BMI and 2D:4D for the left hand, 2D:4D for the right hand and the aggressiveness assessed in the questionnaire, the situation is the same, Pearson ( $r$ ) having negligible values of $0.004,-0.001$ and -0.036 , respectively.

Table 4 shows the Pearson correlations of aggression and BMI for the group of girls. We can notice, for the $2 \mathrm{D}: 4 \mathrm{D}$ ratio, that the correlation is 0.246 for the right and left hand, the aggressiveness assessment has a negative correlation of -0.086, and BMI also has a negative correlation of -0.019 . 
Regarding the questionnaire applied to teachers, we can notice for both groups, boys and girls, low correlation values that, in the best case, can be included in a low negative (positive) correlation, the main conclusion being that teachers are subjective when assessing children.

Table 1. Demographic and aggression-related data for the group of boys

\begin{tabular}{lccccccc}
\hline & $\begin{array}{c}\text { Age } \\
(\text { years })\end{array}$ & $\begin{array}{c}\text { Height } \\
(\mathrm{cm})\end{array}$ & $\begin{array}{c}\text { Weight } \\
(\mathrm{kg})\end{array}$ & $\begin{array}{c}\text { BMI } \\
(\mathrm{kg} / \mathrm{m} 2)\end{array}$ & $\begin{array}{c}\text { 2D:4D - } \\
\text { Left }\end{array}$ & $\begin{array}{c}\text { 2D:4D - } \\
\text { Right }\end{array}$ & $\begin{array}{c}\text { Aggression } \\
(1-5)\end{array}$ \\
\hline Number of values & 102 & 102 & 102 & 102 & 102 & 102 & 102 \\
Mean & 8.10 & 133.40 & 29.61 & 16.35 & 0.98 & 1.00 & 2.28 \\
Coefficient of variation & $15.97 \%$ & $6.85 \%$ & $28.77 \%$ & $17.59 \%$ & $4.17 \%$ & $4.76 \%$ & $58.56 \%$ \\
\hline
\end{tabular}

Table 2. Demographic and aggression-related data for the group of girls

\begin{tabular}{lccccccc}
\hline & $\begin{array}{c}\text { Age } \\
(\text { years })\end{array}$ & $\begin{array}{c}\text { Height } \\
(\mathrm{cm})\end{array}$ & $\begin{array}{c}\text { Weight } \\
(\mathrm{kg})\end{array}$ & $\begin{array}{c}\text { BMI } \\
(\mathrm{kg} / \mathrm{m} 2)\end{array}$ & $\begin{array}{c}\text { 2D:4D - } \\
\text { Left }\end{array}$ & $\begin{array}{c}\text { 2D:4D - } \\
\text { Right }\end{array}$ & $\begin{array}{c}\text { Aggression } \\
(1-5)\end{array}$ \\
\hline Number of values & 98 & 98 & 98 & 98 & 98 & 98 & 98 \\
Mean & 8.12 & 129.80 & 28.04 & 16.39 & 0.99 & 0.99 & 1.86 \\
Std. deviation & 1.27 & 8.86 & 7.51 & 2.70 & 0.04 & 0.04 & 1.10 \\
Coefficient of variation & $15.64 \%$ & $6.82 \%$ & $26.77 \%$ & $16.45 \%$ & $3.79 \%$ & $3.98 \%$ & $59.39 \%$ \\
\hline
\end{tabular}

Table 3. Pearson correlations of aggression and BMI for the group of boys

\begin{tabular}{lcccc}
\hline & 2D:4D - Left & 2D:4D - Right & Aggression (1-5) & BMI (kg/m2) \\
\hline 2D:4D - Left & & 0.196 & 0.035 & 0.004 \\
2D:4D - Right & 0.196 & & -0.141 & -0.001 \\
Aggression (1-5) & 0.035 & -0.141 & & -0.036 \\
BMI (kg/m2) & 0.004 & -0.001 & -0.036 & \\
\hline
\end{tabular}

Table 4. Pearson correlations of aggression and BMI for the group of girls

\begin{tabular}{lcccc}
\hline & 2D:4D - Left & 2D:4D - Right & Aggression (1-5) & BMI $(\mathrm{kg} / \mathrm{m} 2)$ \\
\hline 2D:4D - Left & & 0.246 & -0.086 & -0.019 \\
2D:4D - Right & 0.246 & & -0.100 & -0.128 \\
Aggression (1-5) & -0.086 & -0.100 & & 0.093 \\
BMI (kg/m2) & -0.019 & -0.128 & 0.093 & \\
\hline
\end{tabular}

\section{Conclusion}

After interpreting the correlation coefficient, we can state that, for the 2D:4D test, the results ( 0.196 for boys and 0.246 for girls) can be framed in a negligible correlation according to the Pearson coefficient interpretation scale.

Interpretation of the correlation coefficient ( $r$ ) for the aggressiveness assessed by teachers: in the case of the group of boys, $r$ has a negligible correlation of 0.035 for the left and right hand, while in the case of the group of girls, we can notice a low negative correlation of -0.086 . Therefore, we can conclude that the assessment made by teachers might have been subjective due to their daily contact with students. The 2D:4D ratio highlighted the levels of aggression of the tested groups, and for the second hypothesis, there was no correlation with BMI results. 
In both boys and girls, for the 2D:4D ratio, the coefficient of variation has an intermediate variation, but when related to the questionnaire, we notice a varied distribution and, as stated before, teachers' subjectivity might be a factor influencing our results. Also, in the case of the questionnaire, the levels of aggressiveness are below average.

In relation to the study conducted by Butovskaya et al. (2013), higher aggressiveness levels can be noted in both boys and girls, the reasons being presented in the description of the results.

$\mathrm{BMI}$ in relation to the levels of aggressiveness shows negligible values $(0.004,-0.001$, 0.036 for boys and $0.246,-0.086,-0.019$ for girls) after applying the Pearson correlation coefficient.

The importance of this aspect has led us to try to assess the levels of aggressiveness in children, because aggressive behaviour may have negative implications during classes in the short term and the long term. By perpetuating this type of behaviour, children are likely to face social problems to which they might not be able to find an appropriate response in their daily lives.

\section{References}

Archer, J. (2009). Does sexual selection explain human sex differences in aggression? Behavioral and Brain Sciences, 32(3-4), 249-266. https://doi.org/10.1017/s0140525x09990951

Bailey, A. A., \& Hurd, P. L. (2004). Finger length ratio (2D:4D) correlates with physical aggression in men but not in women. Biological Psychology, 68(3), 215-222. https://doi.org/10.1016/j.biopsycho.2004.05.001

Berenbaum, S. A., \& Resnick, S. M. (1997). Early androgen effects on aggression in children and adults with congenital adrenal hyperplasia. Psychoneuroendocrinology, 22(7), 505-515. https://doi.org/10.1016/s0306-4530(97)00049-8

Björkqvist, K. (2017). Gender differences in aggression. Current Opinion in Psychology, 19, 39-42. https://doi.org/10.1016/j.copsyc.2017.03.030

Butovskaya, M., Fedenok, J., Burkova, V., \& Manning, J. (2013). Sex differences in 2D:4D and aggression in children and adolescents from five regions of Russia. American Journal of Physical Anthropology, 152(1), 130-139. https://doi.org/10.1002/ajpa.22337

Cohen-Bendahan, C. C. C., van de Beek, C., \& Berenbaum, S. A. Prenatal sex hormone effects on child and adult sex-typed behavior: Methods and findings. Neuroscience \& Biobehavioral Reviews, 29, 353-384. https://doi.org/10.1016/j.neubiorev.2004.11.004

Csatho, A., Osvath, A., Bicsak, E., Karadi, K., Manning, J., \& Kallai, J. (2003). Sex role identity related to the ratio of second to fourth digit length in women. Biological Psychology, 62(2), 147-156. https://doi.org/10.1016/S0301-0511(02)00127-8

Donnellan, M. B., \& and Robins, R. W. (2010). Resilient, overcontrolled, and undercontrolled personality types: Issues and controversies. Social and Personality Psychology Compass, 4(11), 1070-1083. https://doi.org/10.1111/j.1751-9004.2010.00313.x

Donnerstein, E., Slaby, R. G., \& Eron, L. D. (1994). The mass media and youth aggression. In L. D. Eron et al. (Eds.), Reason to hope: A psychosocial perspective on violence \& youth (pp. 219-250). American Psychological Association. https://doi.org/10.1037/10164-010

Gomide, P. I. C. (2004). Parents present, absent fathers. Petropolis: Voices.

Hinkle, D. E., Wiersma, W., \& Jurs, S. G. (2002). Applied statistics for the behavioral sciences (5th ed.). Houghton Mifflin. 
Hönekopp, J., \& Watson, S. (2011). Meta-analysis of the relationship between digit-ratio 2D:4D and aggression. Personality and Individual Differences, 51(4), 381-386. https://doi.org/10.1016/j.paid.2010.05.003

Knickmeyer, R., Baron-Cohen, S., Raggatt, P., \& Taylor, K. (2005). Foetal testosterone, social relationships, and restricted interests in children. The Journal of Child Psychology and Psychiatry, 46(2), 198-210. https://doi.org/10.1111/j.1469-7610.2004.00349.x

Lagerspetz, K. M., Björkqvist, K., \& Peltonen, T. (1988). Is indirect aggression typical of females? Gender differences in aggressiveness in 11- to 12-year-old children. Aggressive Behavior, 14(6), 403-414. http://dx.doi.org/10.1002/1098-2337(1988)14:6<403::AID-AB2480140602>3.0.CO;2-D

Manning, J. T., \& Hill, M. R. (2009). Digit ratio (2D:4D) and sprinting speed in boys. American Journal of Human Biology, 21(2), 210-213. https://doi.org/10.1002/ajhb.20855

Manning, J. T., Scutt, D., Wilson, J., \& Lewis-Jones, D. I. (1998). The ratio of 2nd to 4th digit length: A predictor of sperm numbers and concentrations of testosterone, luteinizing hormone and oestrogen. Human Reproduction, 13(11), 3000-3004. https://doi.org/10.1093/humrep/13.11.3000

Mathews, G. A., Fane, B. A., Conway, G. S., Brook, C. G., \& Hines, M. (2009). Personality and congenital adrenal hyperplasia: Possible effects of prenatal androgen exposure. Hormones and Behavior, 55(2), 285-291. https://doi.org/10.1016/j.yhbeh.2008.11.007

Michelson, L., Sugai, D., Wood, R., \& Kazdin, A. (1983). Social skills assessment and training in children: An empirically based handbook. New York, NY: Plenum Press.

Neave, N., Laing, S., Fink, B., \& Manning, J. T. (2003). Second to fourth digit ratio, testosterone, and perceived male dominance. Proceedings of the Royal Society of London Series B, Biological Sciences, 270(1529), 2167-2172. https://doi.org/10.1098/rspb.2003.2502

Özgülük, S. B., \& Erdur-Baker, Ö. (2010). Gender and grade differences in children's alternative solutions to interpersonal conflict situations. Procedia - Social and Behavioral Sciences, 5, 511-514. https://doi.org/10.1016/j.sbspro.2010.07.134

Pasterski, V., Hindmarsh, P., Geffner, M., Brook, C., Brain, C., \& Hines, M. (2007). Increased aggression and activity level in 3-to 11-year-old girls with congenital adrenal hyperplasia (CAH). Hormones and Behavior, 52(3), 368-374. https://doi.org/10.1016/j.yhbeh.2007.05.015

Pereira Falcão, A., \& Turini Bolsoni-Silva, A. (2015). Intervention in social skills: The behavior of children from the perspective of parents and teachers. Journal of Education, Society \& Behavioural Science, 11(3), 1-18. https://doi.org/10.9734/BJESBS/2015/20033

Ramírez-Granizo, I. A., Zurita-Ortega, F., Ubago-Jiménez, J. L., \& Sánchez-Zafra, M. (2019). The association between violent behavior, academic performance, and physical activity according to gender in scholars. Sustainability, 11(15): 4071. https://doi.org/10.3390/su11154071 